\title{
Promoting Social Interactions and Responses to Peer Initiations of a Child with Autism Spectrum Disorder
}

\author{
Kazuki Niwayama',2, Junko Tanaka-Matsumi ${ }^{1}$ \\ ${ }^{1}$ Department of Psychological Science, Kwansei Gakuin University, Nishinomiya, Japan \\ 2 Japan Society for the Promotion of Science, Tokyo, Japan \\ Email: kniwayama@kwansei.ac.jp
}

Received 11 May 2016; accepted 17 June 2016; published 21 June 2016

Copyright (C) 2016 by authors and Scientific Research Publishing Inc.

This work is licensed under the Creative Commons Attribution International License (CC BY). http://creativecommons.org/licenses/by/4.0/

(c) (†) Open Access

\begin{abstract}
The purpose of this case study was to promote the social interaction and responsiveness to peer initiations of a child with autism spectrum disorder (ASD). The study was conducted during the school recess at a Japanese elementary school. A child with ASD in a special needs education class and three peers in a general education class participated. Following a pre-assessment, we contrived joint playtime for the child with ASD and her peers. We then introduced a social skills training component at the beginning of each playtime for both the child with ASD and her peers. During the pre-assessment, no social interaction was observed for the child with ASD. After contriving the joint playtime, the social interaction between the child with ASD and the peers was observed. Conducting the social skills training further increased the social interaction and improved the responsiveness to peer initiations. To evaluate generality of the intervention effects, we observed the social interaction of the child with ASD when she participated in the inclusive general education class. We also observed her on-task behavior in the general education class to see whether her performance in the class improved after the intervention. Both her social interaction and her on-task behavior increased after the intervention. Implications for future study are discussed.
\end{abstract}

\section{Keywords}

Autism Spectrum Disorder, General Education Class, Social Interaction, Social Skills Training

\section{Introduction}

Children with autism spectrum disorder (ASD) have difficulties with social communication and social interaction 
(American Psychiatric Association, 2013). Studies report that children with ASD rarely engage in peer interaction, while their typically developing peers frequently engage in peer interaction (Corbett, Schupp, Simon, Ryan, \& Mendoza, 2010; Koegel, Koegel, Frea, \& Fredeen, 2001). Even when they are placed in a playground setting with peers, children with ASD are rarely observed to engage in peer interaction without specific intervention (Gutierrez, Hale, Gossens-Archuleta, \& Sobrino-Sanchez, 2007). A low level of peer interaction often results in an inability to create stable peer relationships (Strain \& Schwartz, 2001), and unstable peer relationships are related to later maladjustment (Ladd, 2005: pp. 334-336).

Chorpita and Daleiden (2009) reported that all randomized control trial studies for children with ASD that spanned a period of 41 years focused on communication skills. A numerous single case research design studies also have been conducted to improve social interactions of children with ASD. The intervention strategies include peer initiation and teacher antecedent strategies (Odom \& Strain, 1986), prompting and social reinforcement (Gena, 2006), teaching peers pivotal response training procedures (Harper, Symon, \& Frea, 2008; Pierce \& Schreibman, 1995; Pierce \& Schreibman, 1997), video modeling (Buggey, Hoomes, Sherberger, \& Williams, 2009), peer incidental teaching (McGee, Almeida, Sulzerazaroff, \& Feldman, 1992), and social skills training (Goldstein, Kaczmarek, Pennington, \& Shafer, 1992; Kamps et al., 2002).

The majority of these social skills interventions for children with ASD have focused on social interaction initiation (Camargo, Rispoli, Ganz, Hong, Davis, \& Mason, 2014). Relatively few studies have focused on response to peer initiation, although children with ASD tend to respond inconsistently to peer initiations (Corbett et al., 2010). Currently, only a few social skills intervention studies for children with ASD have reported responsiveness (response ratio) to peer initiations (e.g., Kamps et al., 1992). If peers have to approach a child with ASD multiple times to gain a response, then that kind of social interaction is not considered "reciprocal" because peer initiations are not reinforced by responses. Considering the importance of reciprocity in peer relationships, increasing immediate responses to peer initiation of children with ASD is important. McGrath, Bosch, Sullivan, and Fuqua (2003) conducted a study that demonstrated improved responses to peer initiations of a child with ASD. They conducted social skills training for both a child with ASD and a group of typically developing peers. The peers were taught to gain the attention of the child with ASD by using appropriate vocal and non-vocal prompts and to maintain his attention. The child with ASD was taught how to play with peers and respond to peer initiations. After the training, peers' initiations and responses made by the child with ASD increased.

We conducted a case study to promote the peer interaction and responsiveness of a child with ASD to peer initiation in a Japanese elementary school. Because no peer interaction was observed for the child with ASD in a pre-assessment conducted during recess, we initially contrived joint playtime with general education peers for her. After contriving joint playtime, we conducted social skills training (SST) for both the child with ASD and the peers in the same setting to further increase the peer interaction and responsiveness of the child with ASD to peer initiations. Target skills of the SST were selected based on the behavioral observation of the child with ASD. To examine whether the intervention effects would generalize to the general education classroom, we observed the peer interaction and the responsiveness to peer initiations of the child with ASD when she was in the general education classroom as part of her daily academic schedule. Additionally, we observed on-task behavior of the child with ASD in the general education class to examine whether her performance in the class improved after the intervention.

\section{Method}

\subsection{Participant}

The participant was a 9-year-old girl (Sara) who had been diagnosed by an external agency as having ASD. Sara attended 4th grade classes in the public elementary school, located in an urban area of Japan. Sara spent most of the school day in the special needs education class, however she participated in the general education class for approximately 1 - 2 hours a day for activities such as physical education, art, music, or homeroom meetings. The teachers reported that Sara had difficulty participating in the general education class and interacting with her classmates (Sara sometimes refused to go to the general education class). Sara typically spoke in one-word sentences, and she could understand simple verbal instructions. She was rarely observed interacting socially with other children, preferring to engage in solitary play (such as drawing) during recess. When peers approached Sara, she often did not respond to a peer initiation and engaged in non-social behaviors (such as continuing to play alone). Peers often had to approach Sara multiple times to gain her response. 


\subsection{Selection of Peers}

Teachers were asked to nominate peers they thought would be likely to initiate interactions with Sara. Based on their recommendations, three 4th grade girls ( 9 - 10 years old) in general education class were selected to participate in the joint playtime with Sara. The peers were asked by the first author to participate in the joint playtime with Sara, and they all agreed to participate.

\subsection{Trainer}

A graduate student majoring in applied behavior analysis served as the trainer. The trainer had been supporting Sara and her classmates for 1 - 2 days per week for 1.5 years.

\subsection{Setting}

The study was conducted during 20-min recess periods in a Japanese elementary school. Sara's special needs education classroom was located on the first floor of the school building, and the general education classroom was located on the third floor. There were 11 children (1st to 6th grade) and three teachers in the special needs education class, and 31 children and one teacher in the general education class. All observations and training sessions during recess were conducted in the special needs education classroom. The room contained many play materials that Sara preferred, such as a trampoline and some balls.

\subsection{Target Behaviors and Data Collection}

All data were collected during the 20-min recess. Data were gathered for 5-min during each session using 20-s intervals procedure. All target behaviors were coded in vivo using MotivAider ${ }^{\circledR}$ developed by Behavioral Dynamics, Inc.

Social interaction. Social interaction was defined as social behaviors that occurred between Sara and the peers as a result of an initiation-response sequence. Initiation was defined as vocal or non-vocal behavior that attempted to prompt a social response. Response was defined as vocal or non-vocal behavior made to acknowledge a reply to the initiation. The number of intervals during which social interaction was observed was divided by the total number of intervals, then multiplied by 100 to yield a percentage.

Responsiveness to peers. Responsiveness to peers was recorded by counting the number of intervals that Sara responded to peer initiations within three seconds. An interval was scored only when Sara responded to peer initiations within three seconds throughout the interval. The number of intervals during which peer initiations were responded to within three seconds by Sara was divided by the number of intervals during which a peer initiation to Sara was observed, then multiplied by 100 to yield a percentage.

\subsection{Procedure}

The study was conducted during a three-month period. The study was consisted of five phases; pre-assessment, first joint playtime, joint playtime + SST, second joint playtime, and post-assessment.

Pre-assessment. At first, we conducted an observation of Sara's social behaviors in her usual school environment during recess as a pre-assessment. The pre-assessment was conducted once per day, 2 - 3 times per week. The usual school environment for Sara during recess was that although she had the opportunity to play with her classmates (including general education classmates), there were no teacher prompts or feedbacks to promote peer interaction. Therefore, she often stayed in the special needs education classroom during recess engaging in solitary play. Sara's general education peers were also not prompted to play in the special needs education classroom located on another floor, although they were allowed to go into the room during recess.

Joint playtime. Because no social interaction was observed for Sara during the pre-assessment, joint playtime with the three general education peers was contrived for Sara in the room that contained play materials. The joint playtime was contrived once per day, 2 - 3 times per week, during the 20-min recess. At the beginning of joint playtime sessions, the trainer invited the peers to the special needs education classroom to play there. After the peers arrived at Sara's special needs education classroom, the trainer encouraged Sara and her peers to play freely in the room with any play materials they chose. The joint playtime lasted approximately 5 - 10 min, depending on when the class before the recess ended. After confirming that the social interaction was observed, the 
trainer gave positive verbal feedback at the end of the session to Sara and the peers for playing well together.

Joint playtime + SST. After the first joint playtime phase, an SST component was introduced at the beginning of each joint playtime for both Sara and the three peers. The joint playtime + SST sessions were conducted once per day, 2 - 3 times per week. Target skills of the SST were selected based on the trainer's observation in the general education class that Sara was more likely to respond to peer initiations 1) when peers approached Sara while looking at her face, 2) when peers pointed to an object or a place. Therefore, the target skills of the SST were "looking at the peer's face when initiating (looking at face skill)" and "pointing to an object or a place with a finger when referring to it (pointing skill)" and "responding to the peers' initiation (response skill)". The SST consisted of video instruction, video modeling, behavioral rehearsal, and feedback. The video started with written and vocal instructions, followed by the trainer performing either "looking at face skill" or "pointing skill" and an adult responding to it. In the behavioral rehearsal, Sara and one of the peers made a pair. The peer performed either "looking at face skill" or "pointing skill" to Sara, and Sara made a response to it. The trainer gave an extra verbal prompt to Sara before she made a response. After Sara made a response, the trainer gave positive verbal feedback to both Sara and the peer. Then, the trainer instructed Sara and the peer to exchange roles and rehearse the same skill. Therefore, this time Sara performed either "looking at face skill” or "pointing skill”, and the peer made a response to it. Sara also received extra verbal prompts for "looking at face skill" and "pointing skill". The other two peers also made a pair to rehearse the target skills in the same procedure. Sara and the peers rehearsed "looking at face skill" and "pointing skill" once per session, and "response skill" twice per session. The SST took approximately 2 - 3 min. After the SST, Sara and the peers were instructed to play freely. The rest of the procedures were the same as those of the joint playtime phase.

After the Joint playtime + SST phase, SST component was withdrawn to test whether acquired social skills would maintain. After this second joint playtime phase, a post-assessment was conducted when the peers came to special needs education classroom without the trainer's prompt.

\subsection{Generalization}

To evaluate generality of the intervention effects, we observed Sara's social interaction and responsiveness to peers when she participated in the general education class. The definitions of social interaction and responsiveness to peers were the same as in the recess. In the general education class, we recorded social interactions between Sara and all classmates (31 children, including the three peers). Sara's responsiveness was also recorded against initiations by all the classmates. Data were collected during the first 15 min of 45 -min class by using 20 -s intervals. All observations were conducted on the same days that the observations during recess were conducted. The behavioral observation in the general education class was conducted 1 - 2 times per day. When the observation was conducted two times per day, the results were averaged to yield one data point.

We also observed Sara's on-task behavior in the general education class to examine whether her performance in the class improved after the intervention. On-task behavior was defined as working on any task as instructed in the class. Before the intervention, Sara often did not respond to social supports from her classmates, and improving her responsiveness to peers was expected to result in the increase of her on-task behavior. Activities in the general education class were physical education, art, music, and homeroom meetings. There was no particular trend in activities between the phases that might have influenced the opportunities for social interaction.

\subsection{Inter-Observer Agreement}

Inter-observer agreement was calculated using data independently recorded by a second observer for $20.0 \%$ of all the sessions in the recess and $15.6 \%$ of all the sessions in the general education class. Percentage agreement was calculated by dividing agreements by agreements plus disagreements, then multiplying by 100 . The average percentage of agreements for social interaction was $85.3 \%$ (range, $73.3 \%$ to $100 \%$ ) in the recess and $95.6 \%$ (range, $80.0 \%$ to $100 \%$ ) in the general education class. The average percentage of agreements for Sara's responsiveness to peers was $90.7 \%$ (range, $86.7 \%$ to $100 \%$ ) in the recess and $97.1 \%$ (range, $85.7 \%$ to $100 \%$ ) in the general education class. The average percentage of agreements for on-task behavior was $86.0 \%$ (range, $80.0 \%$ to 95.8\%).

\section{Results}

Figure 1 shows the results of Sara's social interaction and her responsiveness to peers during recess. Before 


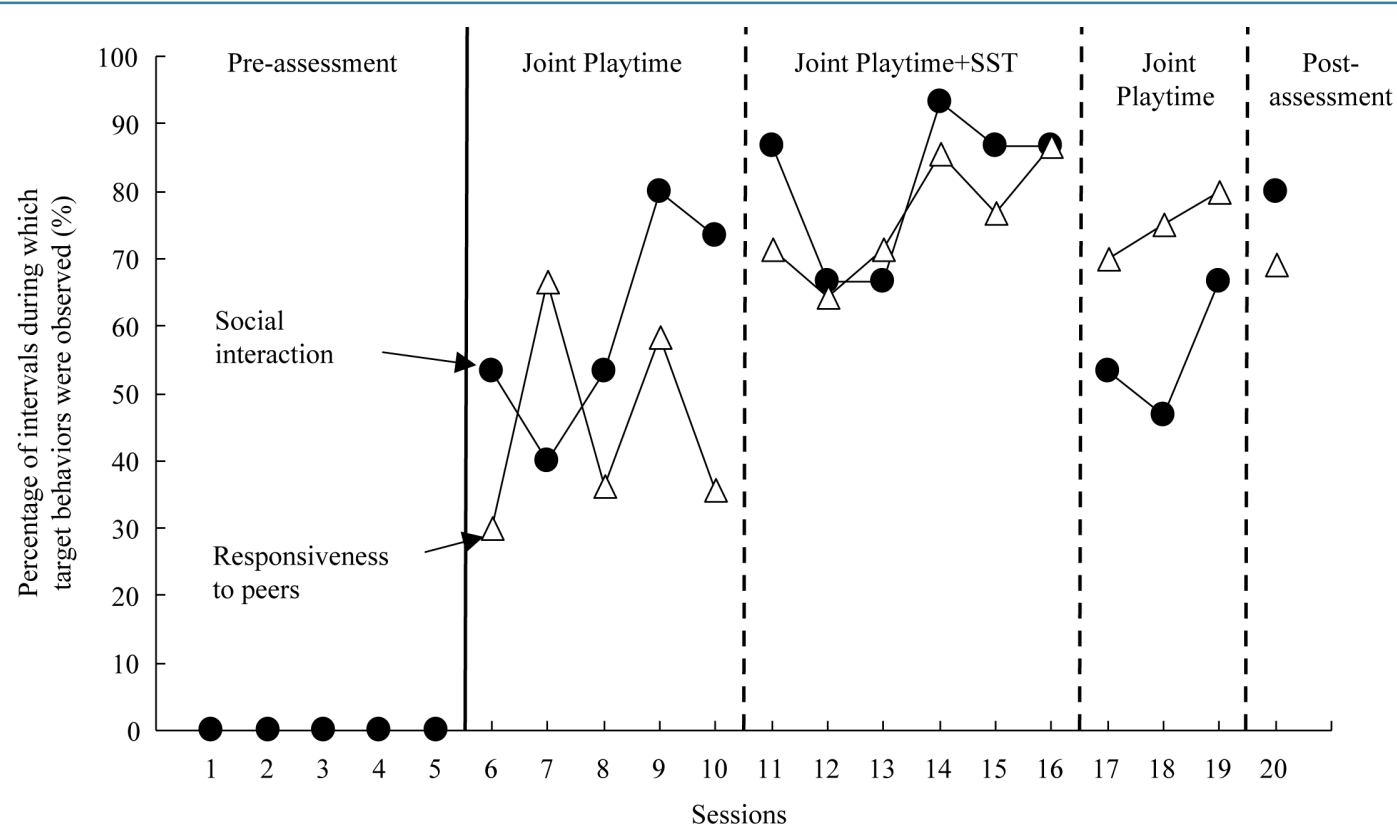

Figure 1. Sara's social behaviors during 20-min recess in the special needs education classroom. Note: The three peers (and other Sara's general education classmates) were not in the same room as Sara during the pre-assessment.

contriving joint playtime, Sara stayed in the special needs education classroom and engaged in solitary play. Social interaction with other children (including Sara's special needs education classmates) was not observed for Sara during the pre-assessment. The three peers (and also other general education classmates) did not come to the special needs education classroom where Sara was during this phase. After contriving the joint playtime with the peers, Sara's social interaction was observed for an average of $60.0 \%$, and Sara's responsiveness to peers was an average of $45.4 \%$. Although there was an upward trend in the social interaction during the first joint playtime phase, we conducted the SST to improve Sara's responsiveness to peers. Conducting the SST further increased the social interaction to an average of $81.1 \%$, and Sara's responsiveness to peers increased to an average of $76.1 \%$. After the SST was withdrawn, the social interaction decreased but remained at an average of $55.6 \%$, and responsiveness to peers was maintained even after the SST was withdrawn at an average of $75.0 \%$. After the second joint playtime, post-assessment was conducted when the peers came to the special needs education classroom to play with Sara without the trainer's prompt. In the post-assessment, the social interaction was observed for $80.0 \%$ of intervals and responsiveness to peers was $69.2 \%$, showing the maintenance of the social skills.

Figure 2 shows the results of Sara's social interaction, responsiveness to peers, and on-task behavior in the general education class. Social interaction between Sara and her classmates increased from an average of 3.3\% in the pre-assessment to $12.5 \%$ in the joint playtime phase, and $19.4 \%$ in the joint playtime + SST phase. Sara's responsiveness to peers in the general education class increased from an average of $30.0 \%$ in the pre-assessment to $73.9 \%$ in the joint playtime phase. After conducting the SST, Sara's responsiveness to peers increased to an average of $93.1 \%$. This rate of Sara's responsiveness to peers was maintained even after the intervention was withdrawn. The on-task behavior also increased after the intervention from an average of $30.4 \%$ in the pre-assessment to $57.4 \%$ in the joint playtime phase, and $68.2 \%$ in the joint playtime + SST phase. This rate of on-task behavior was maintained even after the intervention was withdrawn.

The special needs education teacher rated the acceptability of the intervention on a 5-point scale, with 5 as most acceptable and 1 as least acceptable. Table 1 shows the teacher ratings of the acceptability of the intervention. The teacher rated all 6 items positively, with scores of 4 or higher. In addition, the teacher reported that Sara stopped refusing to go to the general education class, and started to go to the class by herself after the intervention. Two years after the study was ended, the teacher reported that Sara still participated general education class with a help by her peers and played with them when she had opportunities. 


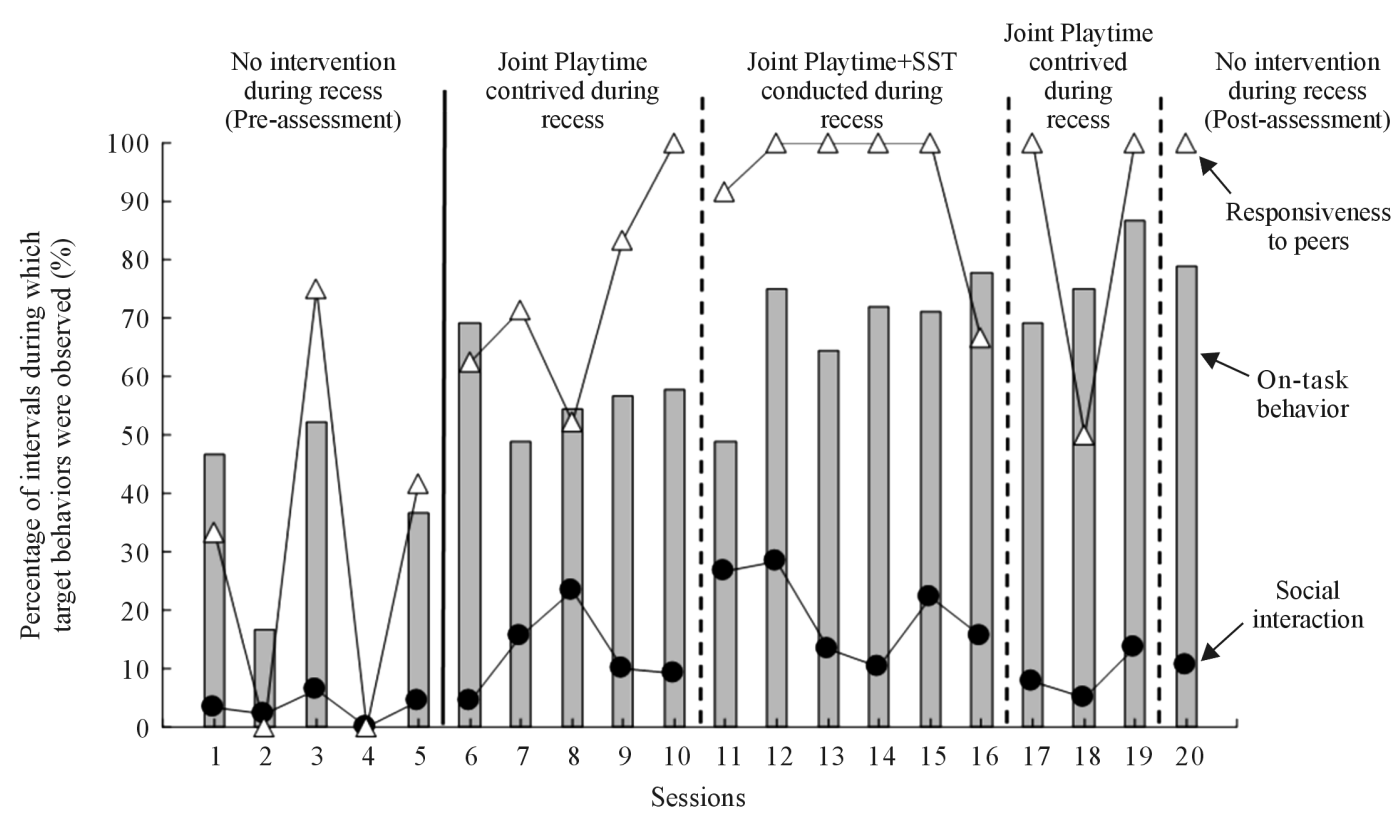

Figure 2. Generalization: Sara's social interaction with classmates (31 children), responsiveness to peers, and on-task behavior in the inclusive general education class across the pre-assessment and training sessions during recess.

Table 1. Teacher ratings of the acceptability of the intervention.

\begin{tabular}{lc}
\hline \multicolumn{1}{c}{ Items } & Ratings \\
\hline 1) Conducting joint playtime and SST project was suitable for the children & 5 \\
2) A lot of time was needed to understand and carry out the procedure in the project. ${ }^{\text {a }}$ & 5 \\
3) I think the project was effective for the child with ASD in terms of supporting her peer interaction & 5 \\
4) If I have an opportunity, I want to carry out the procedure used in the project & 5 \\
5) I think that the project had a positive influence on the children & 5 \\
6) I recommend the procedure to other children in the special needs education class & 4 \\
\hline
\end{tabular}

Note: The ratings that demonstrated the most acceptable condition were scored 5 and the ratings that demonstrated the least acceptable condition were scored $1 .{ }^{\mathrm{a}}$ The item was reversed in scoring.

\section{Discussion}

The results of this case study showed that contriving a joint playtime promoted Sara's social interaction, and conducting the SST further increased her social interaction and responsiveness to peers. Although there was an upward trend in the social interaction during the first joint playtime phase, Sara's responsiveness to peers did not improve during the joint play phase. Before the SST, even though the peers always approached Sara positively, they often had to approach Sara multiple times to gain her response. These social interactions did not seem "reciprocal" because the peers' initiations were not reinforced immediately by Sara's responses. After the SST was conducted, Sara tended to respond to peer initiations immediately. This effect was maintained even after the SST was withdrawn. Currently, only a few studies (e.g., Kamps et al., 1992) report responsiveness (response ratio) to initiations or similar kinds of data. Future studies should use multiple measures to examine whether peer interactions of children with ASD are reciprocal.

After the SST was withdrawn, the social interaction between Sara and the peers decreased. This was because most of the social interactions were initiated by the peers, and their social interaction initiations decreased after the SST was withdrawn. Interacting with Sara in the SST might have reminded the peers to approach Sara during joint playtime + SST phase. 
In the general education class, Sara's social interaction with her classmates and responsiveness to peers increased after the intervention. Sara's on-task behavior in the general education class also increased after the intervention. There are two possible reasons why this was observed. One is that Sara's response to social support from her classmates increased after the intervention, and thus resulted in the increase of her on-task behavior. Another possible reason is that Sara's imitation of her classmates seemed to have been increased. Following the intervention, Sara's teacher reported that Sara would imitate the actions of her classmates more often. It is possible that Sara imitated peers' on-task behavior and that this resulted in the increase in her on-task behavior. In future research, observing and recording imitative behavior of children with ASD should be considered to further analyze this result.

Some limitations to this study should be noted. In the current study, the procedure of joint playtime included multiple components such as having general education peers in the same room as Sara, and the trainer's guidance to promote the social interaction. In future research, having a child with ASD and general education peers in the same room before providing an adult guidance to establish a baseline for joint playtime should be considered. Additionally, when target skills are likely to persist (such as social skills), a multiple baseline design should be used for asserting functional control of the training procedures over responding.

\section{Conclusion}

In conclusion, despite some limitations, the present case study demonstrates the benefit of contriving a joint playtime and brief SST for facilitating peer interactions and responsiveness to peer initiations of a child with ASD in a special needs education class. Increased peer interaction during the recess generalized to the general education classroom with the same peers. The results also demonstrated an increase in on-task behavior of the child with ASD in the general education classroom. These results suggest concrete steps for promoting social interactions of children with ASD and including them in general education classrooms.

\section{References}

American Psychiatric Association (2013). Diagnostic and Statistical Manual of Mental Disorders (5th ed.). Arlington, MA: American Psychiatric Publishing.

Buggey, T., Hoomes, G., Sherberger, M. E., \& Williams, S. (2009). Facilitating Social Initiations of Preschoolers with Autism Spectrum Disorders Using Video Self-Modeling. Focus on Autism and Other Developmental Disabilities, 26, 25-36. http://dx.doi.org/10.1177/1088357609344430

Camargo, S. P. H., Rispoli, M., Ganz, J., Hong, E. R., Davis, H., \& Mason, R. (2014). A Review of the Quality of Behaviorally-Based Intervention Research to Improve Social Interaction Skills of Children with ASD in Inclusive Settings. Journal of Autism and Developmental Disorders, 44, 2096-2116. http://dx.doi.org/10.1007/s10803-014-2060-7

Chorpita, B. F., \& Daleiden, E. L. (2009). Mapping Evidence-Based Treatments for Children and Adolescents: Application of the Distillation and Matching Model to 615 Treatments from 322 Randomized Trials. Journal of Consulting and Clinical Psychology, 77, 566-579. http://dx.doi.org/10.1037/a0014565

Corbett, B. A., Schupp, C. W., Simon, D., Ryan, N., \& Mendoza, S. (2010). Elevated Cortisol during Play Is Associated with Age and Social Engagement in Children with Autism. Molecular Autism, 1, 1-12. http://dx.doi.org/10.1186/2040-2392-1-13

Gena, A. (2006). The Effects of Prompting and Social Reinforcement on Establishing Social Interactions with Peers during the Inclusion of Four Children with Autism in Preschool. International Journal of Psychology, 41, 541-554. http://dx.doi.org/10.1080/00207590500492658

Goldstein, H., Kaczmarek, L., Pennington, R., \& Shafer, K. (1992). Peer-Mediated Intervention: Attending to, Commenting on, and Acknowledging the Behavior of Preschoolers with Autism. Journal of Applied Behavior Analysis, 25, $289-305$. http://dx.doi.org/10.1901/jaba.1992.25-289

Gutierrez Jr., A, Hale, M. N., Gossens-Archuleta, K., \& Sobrino-Sanchez, V. (2007). Evaluating the Social Behavior of Preschool Children with Autism in an Inclusive Playground Setting. International Journal of Special Education, 22, 26-30.

Harper, C. B., Symon, J. B. G., \& Frea, W. D. (2008). Recess Is Time-In: Using Peers to Improve Social Skills of Children with Autism. Journal of Autism and Developmental Disorders, 38, 815-826. http://dx.doi.org/10.1007/s10803-007-0449-2

Kamps, D. M., Leonard, B. R., Vernon, S., Dugan, E. P., Delquadri, J. C., Gershon, B., Wade, L., \& Folk, L. (1992). Teaching Social Skills to Students with Autism to Increase Peer Interactions in an Integrated First-Grade Classroom. Journal of Applied Behavior Analysis, 25, 281-288. http://dx.doi.org/10.1901/jaba.1992.25-281 
Kamps, D., Royer, J., Dugan, E., Kravitz, T., Gonzalez-Lopez, A., Garcia, J., Carnazzo, K., Morrison, L., \& Kane, L. (2002). Peer Training to Facilitate Social Interaction for Elementary Students with Autism and Their Peers. Exceptional Children, 68, 173-187.

Koegel, L. K., Koegel, R. L., Frea, W. D., \& Fredeen, R. M. (2001). Identifying Early Intervention Targets for Children with Autism in Inclusive School Settings. Behavior Modification, 25, 745-761. http://dx.doi.org/10.1177/0145445501255005

Ladd, G. W. (2005). Children's Peer Relations and Social Competence. New Haven: Yale University Press.

McGee, G. G., Almeida, M. C., Sulzer-Azaroff, B., \& Feldman, R. S. (1992). Promoting Reciprocal Interactions via Peer Incidental Teaching. Journal of Applied Behavior Analysis, 25, 117-126. http://dx.doi.org/10.1901/jaba.1992.25-117

McGrath, A. M., Bosch, S., Sullivan, C. L., \& Fuqua, R. W. (2003). Training Reciprocal Social Interactions between Preschoolers and a Child with Autism. Journal of Positive Behavior Interventions, 5, 47-54. http://dx.doi.org/10.1177/10983007030050010701

Odom, S. L., \& Strain, P. S. (1986). A Comparison of Peer-Initiation and Teacher-Antecedent Interventions for Promoting Reciprocal Social Interaction of Autistic Preschoolers. Journal of Applied Behavior Analysis, 19, 59-71.

http://dx.doi.org/10.1901/jaba.1986.19-59

Pierce, K., \& Schreibman, L. (1995). Increasing Complex Social Behaviors in Children with Autism: Effects of PeerImplemented Pivotal Response Training. Journal of Applied Behavior Analysis, 28, 285-295. http://dx.doi.org/10.1901/jaba.1995.28-285

Pierce, K., \& Schreibman, L. (1997). Multiple Peer Use of Pivotal Response Training to Increase Social Behaviors of Classmates with Autism: Results from Trained and Untrained Peers. Journal of Applied Behavior Analysis, 30, 157-160. http://dx.doi.org/10.1901/jaba.1997.30-157

Strain, P., \& Schwartz, I. (2001). ABA and the Development of Meaningful Social Relations for Young Children with Autism. Focus on Autism and Other Developmental Disabilities, 16, 120-128. http://dx.doi.org/10.1177/108835760101600208

\section{Submit or recommend next manuscript to SCIRP and we will provide best service for you:}

Accepting pre-submission inquiries through Email, Facebook, Linkedin, Twitter, etc A wide selection of journals (inclusive of 9 subjects, more than 200 journals)

Providing a 24-hour high-quality service

User-friendly online submission system

Fair and swift peer-review system

Efficient typesetting and proofreading procedure

Display of the result of downloads and visits, as well as the number of cited articles

Maximum dissemination of your research work

Submit your manuscript at: http://papersubmission.scirp.org/ 